\title{
Simulation of developmental changes in action potentials with ventricular cell models
}

\author{
Hitomi Itoh · Yasuhiro Naito $\cdot$ Masaru Tomita
}

Received: 26 October 2005/Revised: 15 May 2006/ Accepted: 22 June 2006/Published online: 16 November 2006

(C) Springer Science+Business Media B.V. 2006

\begin{abstract}
During cardiomyocyte development, early embryonic ventricular cells show spontaneous activity that disappears at a later stage. Dramatic changes in action potential are mediated by developmental changes in individual ionic currents. Hence, reconstruction of the individual ionic currents into an integrated mathematical model would lead to a better understanding of cardiomyocyte development. To simulate the action potential of the rodent ventricular cell at three representative developmental stages, quantitative changes in the ionic currents, pumps, exchangers, and sarcoplasmic reticulum (SR) $\mathrm{Ca}^{2+}$ kinetics were represented as relative activities, which were multiplied by conductance or conversion factors for individual ionic systems. The simulated action potential of the early embryonic ventricular cell model exhibited spontaneous activity, which ceased in the
\end{abstract}

H. Itoh · Y. Naito $(\bowtie) \cdot M$. Tomita

Institute for Advanced Biosciences, Keio University,

Fujisawa, Kanagawa 252-8520, Japan

e-mail: ynaito@sfc.keio.ac.jp

H. Itoh · Y. Naito · M. Tomita

Bioinformatics Program, Graduate School of Media and

Governance, Keio University, Fujisawa, Kanagawa

252-8520, Japan

e-mail: ducky@sfc.keio.ac.jp

H. Itoh

Japan Society for the Promotion of Science (DC1)

Tokyo, Japan

Y. Naito $\cdot$ M. Tomita

Department of Environmental Information, Keio

University, Fujisawa, Kanagawa 252-8520, Japan

M. Tomita

e-mail: mt@sfc.keio.ac.jp simulated action potential of the late embryonic and neonatal ventricular cell models. The simulations with our models were able to reproduce action potentials that were consistent with the reported characteristics of the cells in vitro. The action potential of rodent ventricular cells at different developmental stages can be reproduced with common sets of mathematical equations by multiplying conductance or conversion factors for ionic currents, pumps, exchangers, and SR $\mathrm{Ca}^{2+}$ kinetics by relative activities.

Keywords Cardiac ventricular cell $\cdot$ Computer modeling · Development · Electrophysiology · Ion channels $\cdot$ Spontaneous electrical activity

$\begin{array}{ll}\text { Abbreviations } \\ I_{\mathrm{CaL}} & \mathrm{L} \text {-type } \mathrm{Ca}^{2+} \text { current } \\ I_{\mathrm{CaT}} & \mathrm{T} \text {-type } \mathrm{Ca}^{2+} \text { current } \\ I_{\mathrm{NaCa}} & \mathrm{Na}^{+} / \mathrm{Ca}^{2+} \text { exchange current } \\ I_{\mathrm{NaK}} & \mathrm{Na}^{+} / \mathrm{K}^{+} \text {pump current } \\ I_{\mathrm{Na}} & \mathrm{Na}^{+} \text {current } \\ I_{\mathrm{bNSC}} & \text { background non-selective cation current } \\ I_{\mathrm{I}(\mathrm{Ca})} & \mathrm{Ca}^{2+} \text {-activated background cation current } \\ I_{\mathrm{Cab}} & \text { background } \mathrm{Ca}^{2+} \text { current } \\ I_{\mathrm{KATP}} & \text { ATP-sensitive } \mathrm{K}^{+} \text {current } \\ I_{\mathrm{K} 1} & \text { inward rectifier } \mathrm{K}^{+} \text {current } \\ I_{\mathrm{Kr}} & \text { delayed rectifier } \mathrm{K}^{+} \text {current, rapid } \\ & \text { component } \\ I_{\mathrm{Ks}} & \text { delayed rectifier } \mathrm{K}^{+} \text {current, slow } \\ & \text { component } \\ I_{\mathrm{Kpl}} & \text { non-specific, voltage-dependent outward } \\ & \text { current } \\ I_{\mathrm{to}} & \text { transient outward current } \\ I_{\text {ha }} & \text { hyperpolarization-activated cation current } \\ I_{\mathrm{KACh}} & \text { ACh-activated } \mathrm{K}^{+} \text {current }\end{array}$




\begin{tabular}{|c|c|}
\hline SR & sarcoplasmic reticulum \\
\hline$I_{\text {SR,uptake }}$ & $\mathrm{Ca}^{2+}$ uptake in the SR \\
\hline$I_{\mathrm{SR}, \text { leak }}$ & $\mathrm{Ca}^{2+}$ leak from the $\mathrm{SR}$ \\
\hline$I_{\mathrm{SR}, \text { transfer }}$ & $\begin{array}{l}\mathrm{Ca}^{2+} \text { transfer from the SR uptake site to } \\
\text { the release site }\end{array}$ \\
\hline$I_{\mathrm{RyR}}$ & $\begin{array}{l}\mathrm{Ca}^{2+} \text { release through the RyR channel in } \\
\mathrm{SR}\end{array}$ \\
\hline$I_{\text {ext }}$ & $\begin{array}{l}\text { current applied externally through the } \\
\text { electrode }\end{array}$ \\
\hline$C_{\mathrm{m}}$ & cell capacitance \\
\hline$V_{\mathrm{i}}$ & cell volume accessible for ion diffusion \\
\hline$V_{\text {rel }}$ & volume of SR release site \\
\hline$V_{\text {up }}$ & volume of SR uptake site \\
\hline MDP & maximum diastolic potential \\
\hline $\mathrm{BCL}$ & basic cycle length \\
\hline DP & depolarization phase \\
\hline $\mathrm{RP}$ & repolarization phase \\
\hline DSD & diastolic slow depolarization \\
\hline APD & action potential duration \\
\hline
\end{tabular}

\section{Background}

During vertebrate embryonic development, the heart is the first functional organ to provide nourishment to the developing vertebrate, as an indispensable part of the circulatory system. At a cellular level, early embryonic ventricular cells fire spontaneous action potentials, which eventually disappear at later stages of development (Yokoshiki and Tohse 2001). Dramatic changes in action potential are mediated by the ion channels of the cells. Although developmental changes of such electrophysiological properties have been reported, most have been investigated in individual ion channels; a detailed scheme of cardiomyocyte development has yet to be drawn up.

Developmental changes in ionic currents are reported both at a transcript level and as electrophysiological data. At a transcript level, the ionic channels undergo complex regulation, including subtype switching (Ferron et al. 2002; Nagashima et al. 2001; Franco et al. 2001; Niwa et al. 2004) and alternative splicing (Klugbauer et al. 2002). Despite this complex regulation, the current-voltage $(I-V)$ relationships of the ionic channels do not change significantly among different developmental stages (Ferron et al. 2002; Davies et al. 1996; Kato et al. 1996; Liu et al. 2002; Masuda and Sperelakis 1993). In addition, the $I-V$ relationships of the ionic channels are well conserved among different rodents (Linz and Meyer 2000; Zhang et al. 1994). On the basis of these reports, we make the reasonable assumption that developmental changes in the ion channels can be represented quantitatively as the activities of the channels in the developing rodent relative to those in the adult.

Simulation of cardiac action potential with electrophysiological models has provided a wealth of novel knowledge over the past few decades (Puglisi et al. 2004). Hence, reconstruction of the electrophysiological properties of the individual ionic currents into an integrated mathematical model facilitates our understanding of the developmental changes in cardiac action potential. Here, we show that action potential at different developmental stages can be reproduced with common sets of mathematical models, wherein quantitative changes in the ionic currents, pumps, exchangers, and sarcoplasmic reticulum (SR) $\mathrm{Ca}^{2+}$ kinetics are expressed as relative activities. The models constructed are available online at http://www.ecdn. e-cell.org.

\section{Methods}

General approach to modeling of different developmental stages

Simulating of action potentials at different developmental stages were constructed on the basis of the Kyoto model, an electrophysiological model of the guinea pig cardiomyocyte (Matsuoka et al. 2003). In it, all ionic currents, pumps, exchangers, and SR $\mathrm{Ca}^{2+}$ kinetics are expressed in mathematical equations, which include either a conversion factor $(\mathrm{pA} / \mathrm{mM})$ or conductance $(\mathrm{pA} / \mathrm{mV})$ as one of the parameters.

Various in vitro experimental data, including $I-V$ curves and Western blot analyses, were utilized to estimate the relative activities of ionic currents, pumps, exchangers, and $\mathrm{SR} \mathrm{Ca}^{2+}$ kinetics. Those in vitro experimental studies using guinea pigs were preferentially adopted because the Kyoto model was constructed using the adult guinea pig (Matsuoka et al. 2003). Although this was the preferred experimental animal, data from the rat and mouse were also utilized on the basis of the reported observation that the $I-V$ relationships of the ionic channels are well conserved among different rodents (Linz and Meyer 2000; Zhang et al. 1994). In addition, the target stages for simulation of action potentials were set to early embryonic, late embryonic, and neonatal, because plenty of literature was available for these stages. The early embryonic stage represents approximately the mouse at 9.5 days postcoitum (dpc) and the rat at $11.5 \mathrm{dpc}$; the late embryonic and neonatal stages correspond to 1-5 days before and after birth, respectively. 
Ionic currents

Developmental changes of ionic currents are usually reported at a transcript level and as electrophysiological data. Although ionic channels undergo complex regulation at a transcript level, the $I-V$ relationship of most currents does not change among different developmental stages (Ferron et al. 2002; Davies et al. 1996; Kato et al. 1996; Liu et al. 2002; Masuda and Sperelakis 1993). Hence, we assumed that developmental changes in ionic currents are determined mainly by their quantitative changes (Fig. 1, Tables 1-3), which can be represented as the activities of the current in developing stages relative to that in the adult stage.

The relative activities of ionic currents were either computed from $I-V$ curves (Table 1 ) or estimated on the basis of qualitative observations (Table 2). We confirmed that the $I-V$ relationship did not change among different developmental stages for $I_{\mathrm{CaL}}$ (Kato et al. 1996), $I_{\mathrm{CaT}}$ (Ferron et al. 2002), $I_{\mathrm{K} 1}$ (Kato et al. 1996; Masuda and Sperelakis 1993), $I_{\mathrm{Kr}}$ (Davies et al. 1996), $I_{\mathrm{Ks}}\left(\right.$ Davies et al. 1996), and $I_{\mathrm{Na}}($ Davies et al. 1996). The

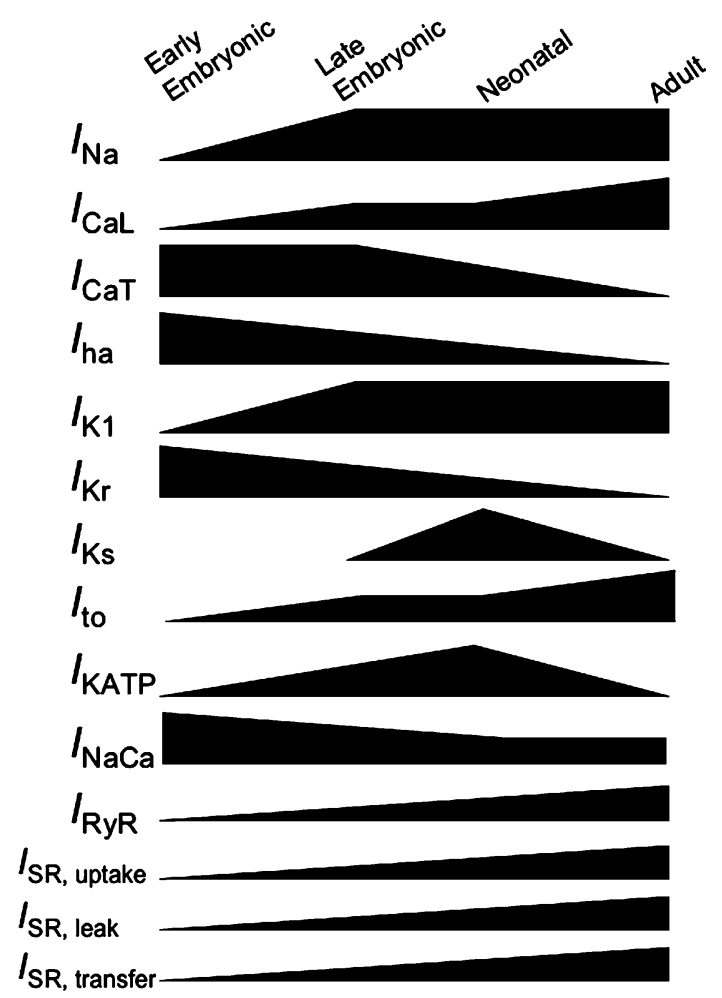

Fig. 1 Schematic diagram for modeling rodent ventricular cells at different stages of development. Early embryonic stage corresponds to approximately $9.5 \mathrm{dpc}$ mouse and 11.5 -dpc rat. Late embryonic stage corresponds to 1-5 days before birth. Neonatal stage corresponds to 1-5 days after birth. The developmental changes are represented as relative activities, which are obtained or estimated from various in vitro experimental data. [All the relative activities are listed in Tables 1-3] relative activities were multiplied by the conversion factor or the conductance of the corresponding ionic current. In addition, all currents listed in Table 1 were normalized by the ratio of the cell capacitance $\left(C_{\mathrm{m}}\right)$ of individual myocytes at the corresponding developmental stages (Table 4) to that of adult ventricular cells $(132 \mathrm{pF})$, because $I-V$ relationships are usually reported as current density ( $\mathrm{pA} / \mathrm{pF})$, and the Kyoto model presents current in pA units. The ratios were $28 / 132$ for the early embryonic ventricular cell model, $35 / 132$ for the late embryonic ventricular cell model, and 40/132 for the neonatal ventricular cell model.

\section{Background ionic currents}

$I_{\mathrm{bNSC}}$ is known to have a higher current density in sinoatrial (SA) node cells than in ventricular cells (Kiyosue et al. 1993). Because we found that $I_{\mathrm{bNSC}}$ plays an important role in the spontaneous action potential of both SA node cells and early embryonic ventricular myocytes, the current amplitudes at different stages were scaled down according to the cell capacitances of the fetal and neonatal cells (Table 2).

$I_{\mathrm{KACh}}$ is known to have negligible effects on the action potential of ventricular cells during the course of development (Davies et al. 1996; Xie et al. 1997). In addition, $I_{\mathrm{KACh}}$ is not included in adult ventricular cell models (Matsuoka et al. 2003). Hence, we excluded $I_{\mathrm{KACh}}$ from the models. Other background currents, including $I_{\mathrm{Kpl}}, I_{\mathrm{I}(\mathrm{Ca})}$, and $I_{\mathrm{Cab}}$ were assumed to have steady current densities; as such, these currents were normalized to the corresponding cell capacitance by the method described above.

\section{Exchangers, pumps, and SR $\mathrm{Ca}^{2+}$ kinetics}

Developmental changes in exchangers, pumps, and SR $\mathrm{Ca}^{2+}$ kinetics are mostly reported as Western blots of the corresponding proteins. Here, we assumed that the relative production levels of the proteins directly reflected the relative ratios of ion fluxes of $\mathrm{Na}^{+} / \mathrm{Ca}^{2+}$ exchange, the SR $\mathrm{Ca}^{2+}$ pump, the ryanodine receptor (RyR) channel, and other SR $\mathrm{Ca}^{2+}$ kinetics; this assumption can be partly supported by the results of previous reports, which imply that the postnatal change in the current density of $\mathrm{Na}^{+}$/ $\mathrm{Ca}^{2+}$ exchange (Artman et al. 1995) is in good agreement with that in the production level of the corresponding protein (Liu et al. 2002; Mahony 1996; Artman 1992). The average relative production values of SR-related proteins in the early embryonic stage (0.04), late embryonic stage (0.30), and neonatal stage ( 0.30$)$ were adopted for estimating those values for $I_{\mathrm{SR} \text {,transfer }}$ and $I_{\mathrm{SR}, \text { leak }}$. 
Table 1 Relative activities for ionic currents, as obtained from the literature

\begin{tabular}{lllllll}
\hline Current & EE & Ref. & LE & Ref. & N & Ref. \\
\hline$I_{\mathrm{Na}}$ & 0.08 & Davies et al. (1996) & 1.00 & Davies et al. (1996) & 1.00 & Davies et al. (1996) \\
$I_{\mathrm{CaL}}$ & 0.46 & Liu et al. (2002) & 0.78 & Kato et al. (1996, Liu et al. 2002) & 0.78 & Kato et al. (1996) \\
$I_{\mathrm{CaT}}$ & 4.50 & Ferron et al. (2002) & 4.50 & Ferron et al. (2002) & 2.90 & Ferron et al. (2002) \\
$I_{\mathrm{K} 1}$ & 0.11 & Masuda and Sperelakis (1993) & 1.00 & Kato et al. (1996) & 1.00 & Kato et al. (1996) \\
$I_{\text {KATP }}$ & 0.32 & Xie et al. (1997) & 0.88 & Xie et al. (1997) & 1.60 & Xie et al. (1997) \\
\hline
\end{tabular}

Relative activities of $I_{\mathrm{Na}}, I_{\mathrm{CaL}}, I_{\mathrm{CaT}}, I_{\mathrm{K} 1}$, and $I_{\mathrm{KATP}}$ for the early embryo (EE), late embryo (LE), and neonatal (N) stage were estimated from the current-voltage $(I-V)$ curves of the cells in vitro. $I-V$ curve of $I_{\mathrm{Na}}$ was obtained from 11- to 13-dpc (early embryonic), and 17- to 20-dpc (late embryonic) mice; expression of $I_{\mathrm{Na}}$ reached the adult level in the late embryonic stage (Davies et al. 1996). For $I_{\mathrm{CaL}}$, the early embryonic $I-V$ curve was obtained from 9.5-dpc mice (Liu et al. 2002); the late embryonic $I-V$ curve was obtained from both 18-dpc mice (Liu et al. 2002) and fetal guinea pigs 1-7 days before birth (Kato et al. 1996); the neonatal $I-V$ curve was obtained from neonatal guinea pigs t 1-5 days after birth (Kato et al. 1996). Relative activities of $I_{\mathrm{CaT}}$ were obtained on the basis of data for the 14-dpc rat, 18-dpc rat, and 1-day-old rat (Ferron et al. 2002), which corresponded to EE, LE, and N, respectively. For $I_{\mathrm{K} 1}, I-V$ curves of the 12-dpc rat (Masuda and Sperelakis 1993), the fetal guinea pig 1-7 days before birth (Kato et al. 1996), and the neonatal guinea pig 1-5 days after birth (Kato et al. 1996) were obtained. Relative activities of $I_{\text {KATP }}$ were obtained on the basis of data for the 12-dpc rat, 18-dpc rat, and 1-day-old rat (Xie et al. 1997)

Table 2 Estimated relative activities of ionic currents

\begin{tabular}{|c|c|c|c|c|c|c|}
\hline Current & $\mathrm{EE}$ & Ref. & LE & Ref. & $\mathrm{N}$ & Ref. \\
\hline$I_{\mathrm{ha}}$ & 100.00 & Yasui et al. (2001) & 18.00 & Yasui et al. (2001) & 0.00 & $\mathrm{n} / \mathrm{a}$ \\
\hline$I_{\mathrm{Kr}}$ & 10.00 & $\begin{array}{l}\text { Spence et al. (1994), } \\
\text { Chun et al. (2004) }\end{array}$ & 2.00 & $\begin{array}{l}\text { Kato et al. (1996), } \\
\text { Wang et al. (1996) }\end{array}$ & 1.50 & $\begin{array}{l}\text { Kato et al. (1996), } \\
\text { Wang et al. (1996) }\end{array}$ \\
\hline$I_{\mathrm{Ks}}$ & 0.01 & Davies et al. (1996) & 0.01 & Davies et al. (1996), Kato et al. (1996) & 2.00 & Kato et al. (1996) \\
\hline$I_{\text {to }}$ & 0.01 & Davies et al. (1996) & 0.27 & Kilborn and Fedida (1990) & 0.27 & Kilborn and Fedida (1990) \\
\hline$I_{\mathrm{bNSC}}$ & 0.35 & $\mathrm{n} / \mathrm{a}$ & 0.43 & $\mathrm{n} / \mathrm{a}$ & 0.49 & $\mathrm{n} / \mathrm{a}$ \\
\hline
\end{tabular}

Relative activities of $I_{\mathrm{ha}}, I_{\mathrm{Kr}}, I_{\mathrm{Ks}}$, and $I_{\mathrm{bNSC}}$ were estimated from various qualitative observations. The conversion factor of $I_{\mathrm{ha}}$ was set to 0 in the adult guinea pig ventricular cell model (Matsuoka et al. 2003); thus the expression levels of $I_{\text {ha }}$ in the early embryonic stage and late embryonic stage were estimated from the $I-V$ curves of $I_{\mathrm{ha}}$ in 9.5- and 18-dpc mice (Yasui et al. 2001). Relative activities of $I_{\mathrm{Kr}}$ and $I_{\mathrm{Ks}}$ were estimated from various in vivo and in vitro experimental data: $I-V$ curve of $I_{\mathrm{K}}$, sum of $I_{\mathrm{Kr}}$ and $I_{\mathrm{Ks}}$ in fetal and neonatal guinea pigs (Kato et al. 1996); $I-V$ curves of $I_{\mathrm{Ks}}$ in 11-13-dpc and 17-20-dpc mice (Davies et al. 1996); qualitative observation using the selective $I_{\mathrm{Kr}}$ blocker dofetilide in 11- and 14.5-dpc rats (Spence et al. 1994; Chun et al. 2004), and in 18-dpc and 1-day-old mice (Wang et al. 1996). For $I_{\text {to }}, I-V$ curves of the 11-dpc mice (Davies et al. 1996) and 1-day-old rat after birth (Kilborn and Fedida 1990) were obtained for the estimation. Because we found that $I_{\mathrm{bNSC}}$ plays an important role in the spontaneous action potential of early embryonic ventricular myocytes, relative activities were estimated from the activity of the current in SA node cells, which was normalized according to the cell capacitances

Table 3 Relative ratios of ion fluxes of exchangers, pumps, and sarcoplasmic reticulum (SR) $\mathrm{Ca}^{2+}$ kinetics

\begin{tabular}{|c|c|c|c|c|c|c|}
\hline Current & $\mathrm{EE}$ & Ref. & LE & Ref. & $\mathrm{N}$ & Ref. \\
\hline $\mathrm{Na}^{+} / \mathrm{Ca}^{2+}$ exchange & 4.95 & Liu et al. (2002) & 1.74 & $\begin{array}{l}\text { Liu et al. (2002), } \\
\text { Artman (1992) }\end{array}$ & 1.00 & $\begin{array}{l}\text { Liu et al. (2002), Artman et al. (1995), } \\
\text { Artman (1992) }\end{array}$ \\
\hline $\mathrm{SR} \mathrm{Ca}^{2+}$ pump & 0.03 & Liu et al. (2002) & 0.21 & $\begin{array}{l}\text { Liu et al. (2002), } \\
\text { Chen et al. (2000) }\end{array}$ & 0.21 & Liu et al. (2002), Chen et al. (2000) \\
\hline RyR channel & 0.05 & Liu et al. (2002) & 0.40 & Liu et al. (2002) & 0.40 & Liu et al. (2002) \\
\hline SR transfer & 0.04 & Liu et al. (2002) & 0.30 & Liu et al. (2002) & 0.30 & Liu et al. (2002) \\
\hline SR leak & 0.04 & Liu et al. (2002) & 0.30 & Liu et al. (2002) & 0.30 & Liu et al. (2002) \\
\hline
\end{tabular}

Developmental change in $\mathrm{Na}^{+} / \mathrm{Ca}^{2+}$ exchange $\left(I_{\mathrm{NaCa}}\right)$ is reported as $I-V$ curves in both the rabbit and guinea pig (Artman et al. 1995) and by Western blots of NCX1 protein in the mouse (Liu et al. 2002) and rabbit (Artman 1992); on the basis of the literature implying that postnatal quantitative changes in the density of $I_{\mathrm{NaCa}}$ are in good agreement with the changes in protein production level, we assumed that the relative production level of the proteins directly reflected the relative ratios of ion fluxes of $I_{\mathrm{NaCa}}$, the SR Ca ${ }^{2+}$ pump $\left(I_{\mathrm{SR}, \text { uptake }}\right)$, and the RyR channel $\left(I_{\mathrm{RyR}}\right)$. Hence, we computed the relative ratios of the current fluxes from Western blots of SR-related proteins (Liu et al. 2002; Chen et al. 2000). The average relative production levels of SR-related proteins in the EE stage (0.04), LE stage (0.30), and $\mathrm{N}$ stage $(0.30)$ were adopted as the relative activities of $I_{\mathrm{SR}, \text { transfer }}$ and $I_{\mathrm{SR} \text {,leak }}$ at these stages 
Table 4 Cell capacitances and volumes of cell compartments

\begin{tabular}{|c|c|c|c|c|c|c|}
\hline Parameter(unit) & $\mathrm{EE}$ & Ref. & LE & Ref. & $\mathrm{N}$ & Ref. \\
\hline$C_{\mathrm{m}}(\mathrm{pF})$ & 28 & Yasui et al. (2001) & 35 & $\begin{array}{l}\text { Kato et al. (1996), } \\
\text { Yasui et al. }(2001)\end{array}$ & 40 & Kato et al. (1996) \\
\hline$V_{\mathrm{i}}(\mu \mathrm{l})$ & $1.697 \times 10^{-3}$ & Huynh et al. (1992) & $2.121 \times 10^{-3}$ & Huynh et al. (1992) & $2.424 \times 10^{-3}$ & Huynh et al. (1992) \\
\hline$V_{\text {rel }}(\mu \mathrm{l})$ & $1.357 \times 10^{-6}$ & Liu et al. (2002) & $1.273 \times 10^{-5}$ & Liu et al. (2002) & $1.454 \times 10^{-5}$ & Liu et al. (2002) \\
\hline$V_{\text {up }}(\mu \mathrm{l})$ & $3.394 \times 10^{-6}$ & Liu et al. (2002) & $3.182 \times 10^{-5}$ & Liu et al. (2002) & $3.636 \times 10^{-5}$ & Liu et al. (2002) \\
\hline
\end{tabular}

$C_{\mathrm{m}}$ values of mouse early embryonic ventricular cells $(28 \mathrm{pF})$, guinea pig late embryonic cells $(35 \mathrm{pF})$, and guinea pig neonatal ventricular cells $(40 \mathrm{pF})$ were adopted (Kato et al. 1996; Yasui et al. 2001). Cell volume $\left(V_{\mathrm{i}}\right)$ was estimated by multiplying adult $V_{\mathrm{i}}$ $\left(8.0 \times 10^{-3} \mu \mathrm{l}\right)$ by the corresponding $C_{\mathrm{m}}(28,35$, or $40 \mathrm{pF})$ over adult $C_{\mathrm{m}}(132 \mathrm{pF})$, on the basis of the report that there is a positive linear correlation between membrane capacitance and cell volume (Huynh et al. 1992). The volume fraction of $V_{\text {rel }}$ and that of $V_{\text {up }}$ to $V_{\mathrm{i}}$ were set on the basis of the average relative expression levels of these proteins in the EE stage (0.04), LE stage (0.30), and $\mathrm{N}$ stage $(0.30)$, as estimated from Western blots of SR-related proteins (Liu et al. 2002)

\section{Cell capacitance and volume of cell compartments}

$C_{\mathrm{m}}$ and volumes $\left(V_{\mathrm{i}}, V_{\text {rel }}, V_{\text {up }}\right)$ were computed on the basis of quantitative data from the literature (Table 4). No significant differences were observed between the $C_{\mathrm{m}}$ of mouse ventricular cells $(31 \pm 3.3 \mathrm{pF})$ and that of guinea pig ventricular cells $(34.5 \pm 2.72 \mathrm{pF})$ in the late embryonic stage (Kato et al. 1996; Yasui et al. 2001). As such, the $C_{\mathrm{m}}$ values for mouse early embryonic ventricular cells $(28 \mathrm{pF})$, guinea pig late embryonic ventricular cells $(35 \mathrm{pF})$, and guinea pig neonatal ventricular cells $(40 \mathrm{pF})$ were adopted.

The developmental change in $V_{\mathrm{i}}$ in rabbit ventricular cells is roughly proportional to that of cell capacitance (Huynh et al. 1992). In addition, a positive linear correlation was found between membrane capacitance and cell volume in several species (Satoh et al. 1996). Hence, cell volume was estimated by multiplying the adult $V_{\mathrm{i}}\left(8.0 \times 10^{-3} \mu \mathrm{l}\right)$ by the corresponding $C_{\mathrm{m}}(28$, 35 , or $40 \mathrm{pF})$ over the adult $C_{\mathrm{m}}(132 \mathrm{pF})$.

In the Kyoto model, the volume fractions of $V_{\text {rel }}$ and $V_{\text {up }}$ were set to $2 \%$ and $5 \%$ of $V_{\mathrm{i}}$, respectively (Matsuoka et al. 2003). The SR-mediated $\mathrm{Ca}^{2+}$ transient is modeled by multiplying an estimated value called the "SA factor" by $V_{\text {rel }}, V_{\text {up }}$, and SR-related currents in the Kyoto model (Matsuoka et al. 2003). The same approach has been adopted for estimating $V_{\text {rel }}$ and $V_{\text {up }}$ in different developmental stages of ventricular cells; on the basis of quantitative changes in SRrelated proteins (Liu et al. 2002), the average relative expression values of those proteins in the early embryonic stage (0.04), late embryonic stage (0.30), and neonatal stage $(0.30)$ were utilized for the estimation.

Simulation of action potential at three different developmental stages

The E-Cell simulation environment version 3.1 (Takahashi et al. 2004) was utilized to simulate the action potential. All of the models were simulated for $200 \mathrm{~s}$ to confirm that the spontaneous action potentials were stable or that the membrane potential had reached a quasi-steady state. Hence, the simulation results presented in this report were recorded after simulating the corresponding models for $200 \mathrm{~s}$. In addition, an external current $\left(I_{\mathrm{ext}}\right)$ was applied in the late embryonic and neonatal ventricular cell models in order to fire the action potential of the cells.

To determine the factors that contribute to the dramatic changes in action potential between early and late embryonic stages, the relative activity of each current was shifted from early embryonic to late embryonic by $10 \%$ increments. We assumed that all of the changes in the current components proceeded steadily between the representative stages. The action potentials were obtained $200 \mathrm{~s}$ after changing the parameters of the original condition.

Modeling and simulation of action potentials in the Luo-Rudy model

Another electrophysiological model, the Luo-Rudy model (Faber and Rudy 2000), was utilized to further validate the simulated result with the Kyoto model. The Luo-Rudy model included all the ionic currents listed in Fig. 1 except $I_{\text {to }}, I_{\mathrm{KATP}}$, and $I_{\text {ha }}$; all relative activities except those of these currents were implemented by the same procedure as used in the Kyoto model. Several background currents were left unchanged, because ionic currents in Luo-Rudy model are presented as current density $(\mu \mathrm{A} / \mu \mathrm{F})$. Cell volumes $\left(V_{\mathrm{i}}, V_{\text {rel }}, V_{\text {up }}\right)$ were computed accordingly by the procedure described above. Because the Luo-Rudy model requires "pacing" of the action potential, the model was simulated for $600 \mathrm{~s}$ as instructed in the report (Faber and Rudy 2000). 


\section{Results}

Simulated action potential at different developmental stages

The early embryonic ventricular cell model exhibited a spontaneous action potential (Fig. 2A). After the maximum diastolic potential (MDP) at $-62.86 \mathrm{mV}$, the membrane potential slowly depolarized until it reached approximately $-40 \mathrm{mV}$, when spontaneous action potential was triggered. The membrane potential then started to repolarize at $3.13 \mathrm{mV}$, and completed repolarization in less than $100 \mathrm{~ms}$. The whole action potential was completed in a basic cycle length (BCL) of $492 \mathrm{~ms}$.

The spontaneous action potential ceased in the later stages of development (Fig. 2B). Both late embryonic and neonatal ventricular cells showed resting membrane potentials that were more hyperpolarized $(-83.60 \mathrm{mV})$ than the MDP of the early embryonic ventricular cell. Repolarization of the action potential occurred more slowly in the late embryonic ventricular cell than in the neonatal ventricular cell; the action potential duration (APD) at $90 \%$ was $140 \mathrm{~ms}$ in the late embryonic ventricular cell and $117 \mathrm{~ms}$ in the neonatal ventricular cell.

Simulated action potential at the early embryonic stage in the Kyoto and Luo-Rudy models

A spontaneous action potential was observed in both the Kyoto (Fig. 3A) and Luo-Rudy models (Fig. 3B). The MDP was more negative in the Luo-Rudy model $(-71.16 \mathrm{mV})$ than in the Kyoto model $(-62.86 \mathrm{mV})$. Repolarization of the spontaneous action potential started from the overshoot at $13.74 \mathrm{mV}$ in the
Luo-Rudy model. Both the depolarization phase (DP) and the repolarization phase (RP) were faster in the Luo-Rudy model, resulting in a shorter BCL (414 ms); differences in simulated action potential were determined by differences in ionic currents.

The dynamic behavior of the ionic currents $\left(I_{\mathrm{CaL}}\right.$ and $I_{\mathrm{Kr}}$ ) observed during action potential simulation is shown in Fig. 3. Ionic currents were expressed by different mathematical equations in the Kyoto and Luo-Rudy models, so the simulated behavior of the ionic currents differed between the models. The sums of $I_{\mathrm{CaL}}$ and $I_{\mathrm{Kr}}$ are shown in Fig. 3. Apparently, activation of $I_{\mathrm{Kr}}$ in RP was faster in the Luo-Rudy (Fig. 3B) than in the Kyoto model (Fig. 3A). Although activation of $I_{\mathrm{CaL}}$ in DP occurred at approximately the same rate in both models, the peak of $I_{\mathrm{CaL}}$ in the Kyoto model was smaller than that of $I_{\mathrm{CaL}}$ in the Luo-Rudy model. In addition to the fact that the $I_{\mathrm{CaL}}$ was larger than the Kyoto model, reactivation of the $I_{\mathrm{CaL}}$ was observed in RP in the Luo-Rudy model.

Effects of shifting relative activities of current components

The spontaneous action potential of early embryonic ventricular cells ceased when the relative activities of all current components were shifted by $10 \%$ or more toward the late embryonic stage value (Fig. 4A).

Shifting the relative activities of $I_{\mathrm{K} 1}$ and $I_{\mathrm{Kr}}$ from early embryonic to late embryonic values contributed to the disappearance of the spontaneous action potential (Figs. 4B, C). The spontaneous action potential ceased when the relative activity of $I_{\mathrm{K} 1}$ was shifted by $10 \%$ or more toward the late embryonic stage values (Fig. 4B). When the relative activity of $I_{\mathrm{K} 1}$ was shifted from $10 \%$ to $80 \%$ toward the late embryonic stage value, the

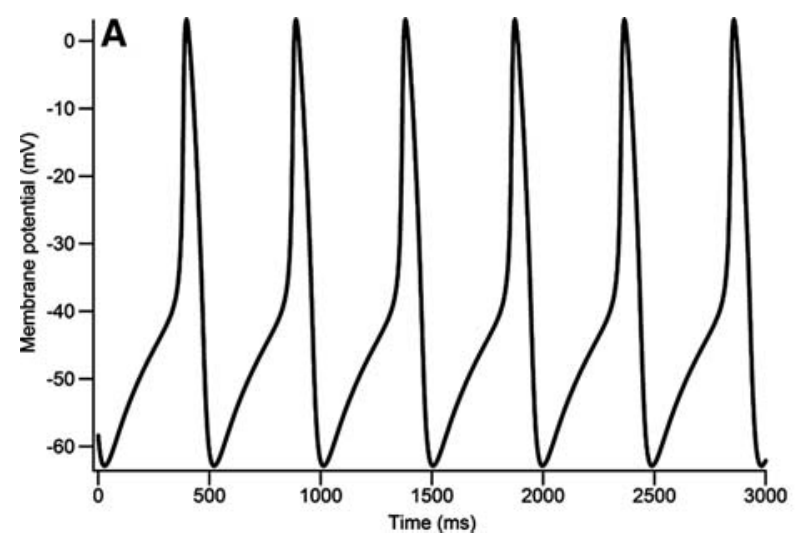

Fig. 2 Simulated action potentials at different developmental stages with the constructed models. (A) Simulated action potential at early embryonic stage. (B) Simulated action

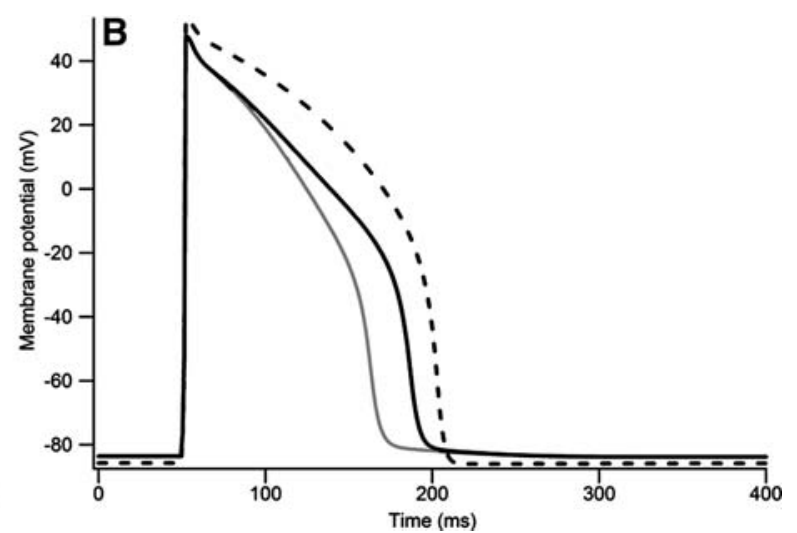

potential at late embryonic stage (dark line) and neonatal stage (light line). Action potential at adult stage is shown as dashed line 


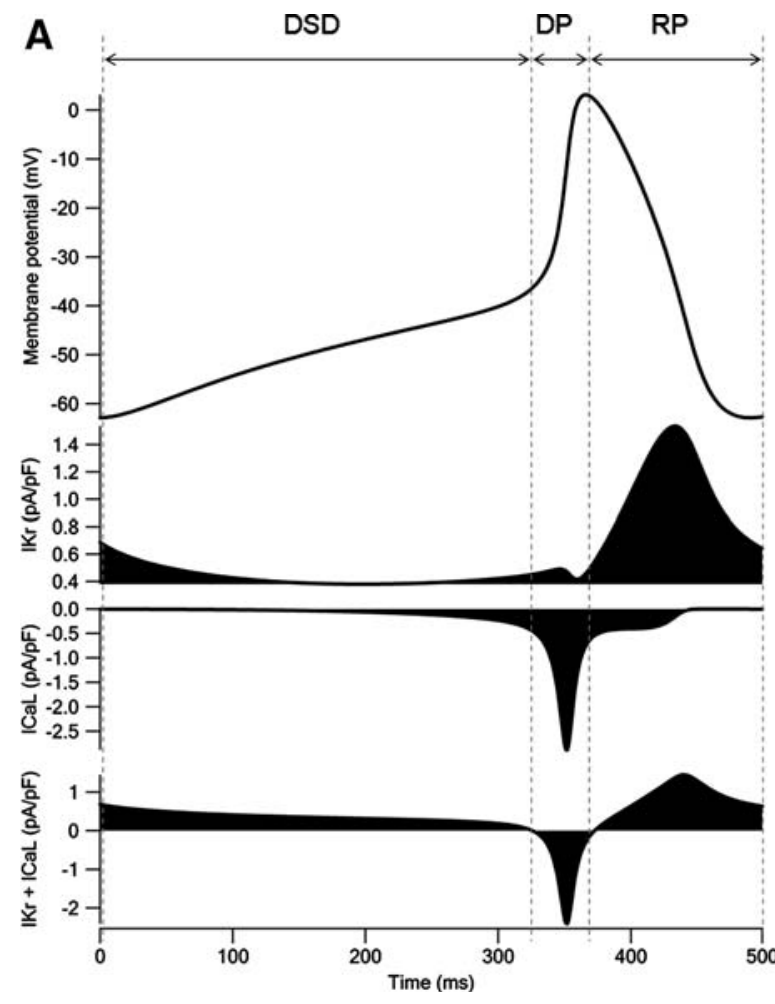

Fig. 3 Simulated action potential and ionic currents at early embryonic stage with two different electrophysiological models. Simulated action potential can be divided into three phases: diastolic slow depolarization (DSD) phase, depolarization phase (DP), and repolarization phase (RP). (A) Simulated action

resting membrane potential became more negative $(-53.69$ to $-58.15 \mathrm{mV})$. In contrast, the spontaneous action potential ceased when the relative activity of $I_{\mathrm{Kr}}$ was shifted by $80 \%$ or more toward the late embryonic stage value (Fig. 4C), at which time the resting membrane potential was $-25.85 \mathrm{mV}$.

The spontaneous action potential did not disappear when the relative activities of all current components except $I_{\mathrm{K} 1}$ and $I_{\mathrm{Kr}}$ were shifted toward the late embryonic stage value (Fig. 4D). The MDP shifted positively from -61.28 to $-47.55 \mathrm{mV}$ when the relative activity was shifted by 10 to $70 \%$ toward the late embryonic stage value. These results further indicate that developmental changes in the relative activities of $I_{\mathrm{K} 1}$ and $I_{\mathrm{Kr}}$ are the sole factors in the disappearance of the spontaneous action potential.

\section{Discussion}

This study provides for the first time computational models simulating the action potential at 3 different developmental stages. We have shown that developmental changes in action potential can be exhibited with the same set of mathematical equations by

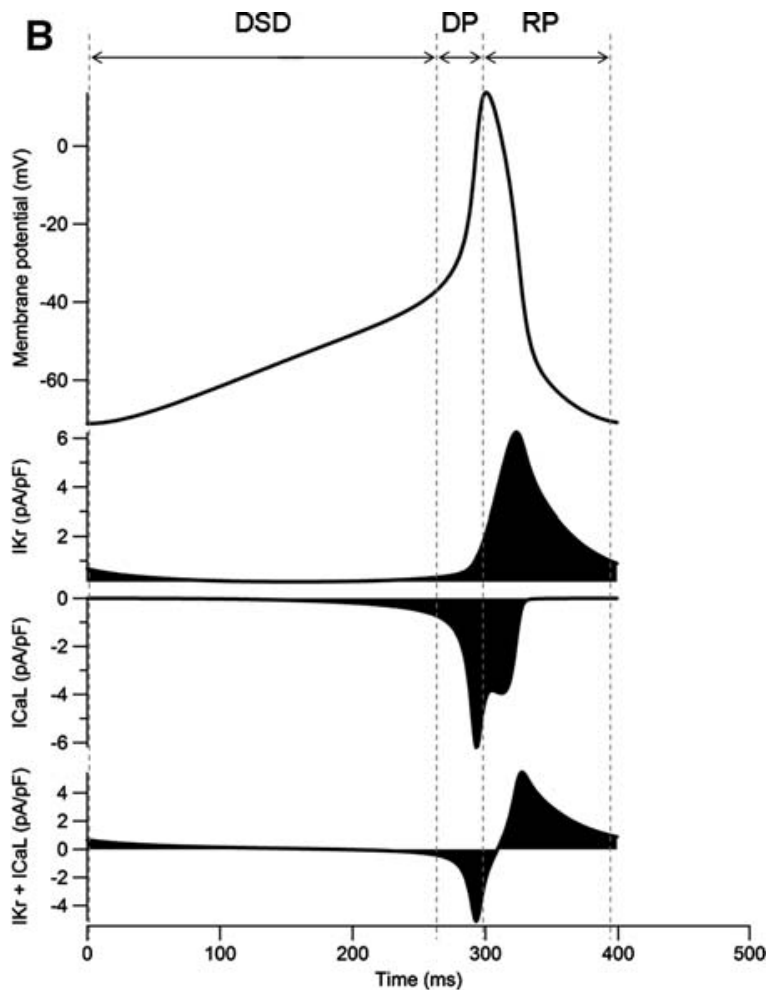

potential, $I_{\mathrm{Kr}}$ current, and $I_{\mathrm{CaL}}$ current in the Kyoto model. (B) Simulated action potential, $I_{\mathrm{Kr}}$ current, and $I_{\mathrm{CaL}}$ current in the Luo-Rudy model. Sum of $I_{\mathrm{Kr}}$ and $I_{\mathrm{CaL}}$ shows that the increase in outward (positive) current is slower in the Kyoto model than in the Luo-Rudy model

multiplying equations for ionic currents, pumps, exchangers, and $\mathrm{SR} \mathrm{Ca}^{2+}$ kinetics by their corresponding relative activities.

Simulated action potential at the early embryonic stage

The early embryonic ventricular cell model reproduced well the spontaneous action potential that is generated by ventricular cells in 12-dpc rats (Nagashima et al. 2001). Species-specific differences in spontaneous action potential waveforms have been observed between ventricular cells in 9.5-dpc mice (Yasui et al. 2001) and 12-dpc rats (Nagashima et al. 2001). The ventricular cells in 9.5-dpc mice generate a more hyperpolarized MDP $(-71.2 \pm 0.4 \mathrm{mV})$ than in 12-dpc rats $(-66.7 \pm 3.6 \mathrm{mV})$. A spontaneous action potential is triggered when the membrane potential reaches approximately $-60 \mathrm{mV}$ in 9.5 -dpc mice and approximately $-40 \mathrm{mV}$ in 12-dpc rats (Nagashima et al. 2001; Yasui et al. 2001). The simulated action potential in our early embryonic ventricular cell model (Fig. 2A) was very similar to the action potential waveforms generated by the automatically beating cells in 12-dpc 

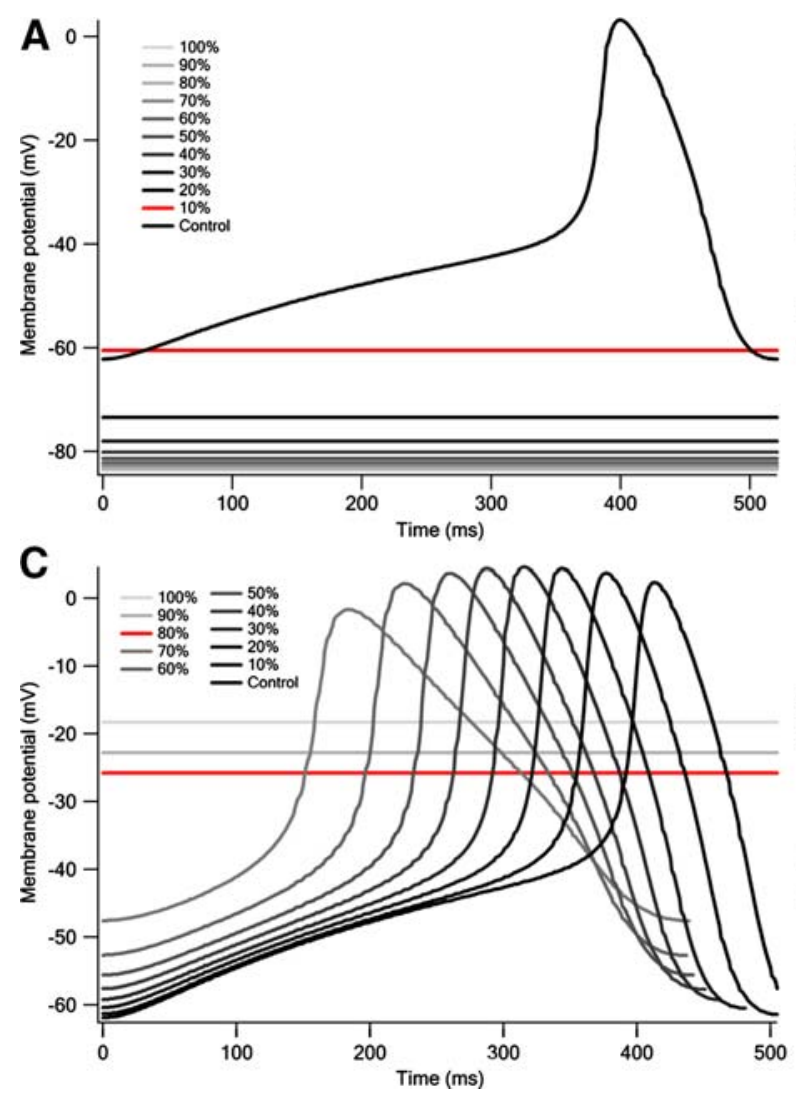

Fig. 4 Effects of shifting relative activities of all current components (A), $\mathrm{I}_{\mathrm{K} 1}(\mathbf{B}), \mathrm{I}_{\mathrm{Kr}}(\mathbf{C})$, and of all current components except $\mathrm{I}_{\mathrm{K} 1}$ and $\mathrm{I}_{\mathrm{Kr}}$ (D). (A) Changes in action potential when shifting relative activities of all currents by $10 \%$ increments. (B) Changes in action potential when shifting from relative activity of early embryonic $I_{\mathrm{K} 1}$ (darkest line) to that of late embryonic $I_{\mathrm{K} 1}$ (lightest line) by $10 \%$ increments. Spontaneous action potential ceased when relative activity of $I_{\mathrm{K} 1}$ was shifted by $10 \%$ (red line) or more toward late embryonic stage value. Dataset could not be obtained when the current was shifted by

rats (Nagashima et al. 2001). In addition, the MDP of the simulated action potential $(-62.86 \mathrm{mV})$ was approximately equal to that of the ventricular cells in 12-dpc rats. Hence, our early embryonic ventricular cell model could reproduce an action potential that was in reasonable agreement with those of previous studies (Nagashima et al. 2001; Yasui et al. 2001).

The speed of the spontaneous action potential in the early embryonic stage is a controversial issue. Unfortunately, the action potential of early embryonic guinea pig ventricular cells has not been reported. Early embryonic hearts have shown a large range of heart rates, from 61 to $219 \mathrm{~min}^{-1}$ in 11.5 -dpc rats (Couch et al. 1969). The BCL of the simulated action potential of our early embryonic ventricular cell model (492 ms) was roughly consistent with that of ventricular cells in 9.5-dpc mice, which is $510.8 \pm 32.8 \mathrm{~ms}$ (Yasui et al. 2001). Although the BCL of the action potential of our
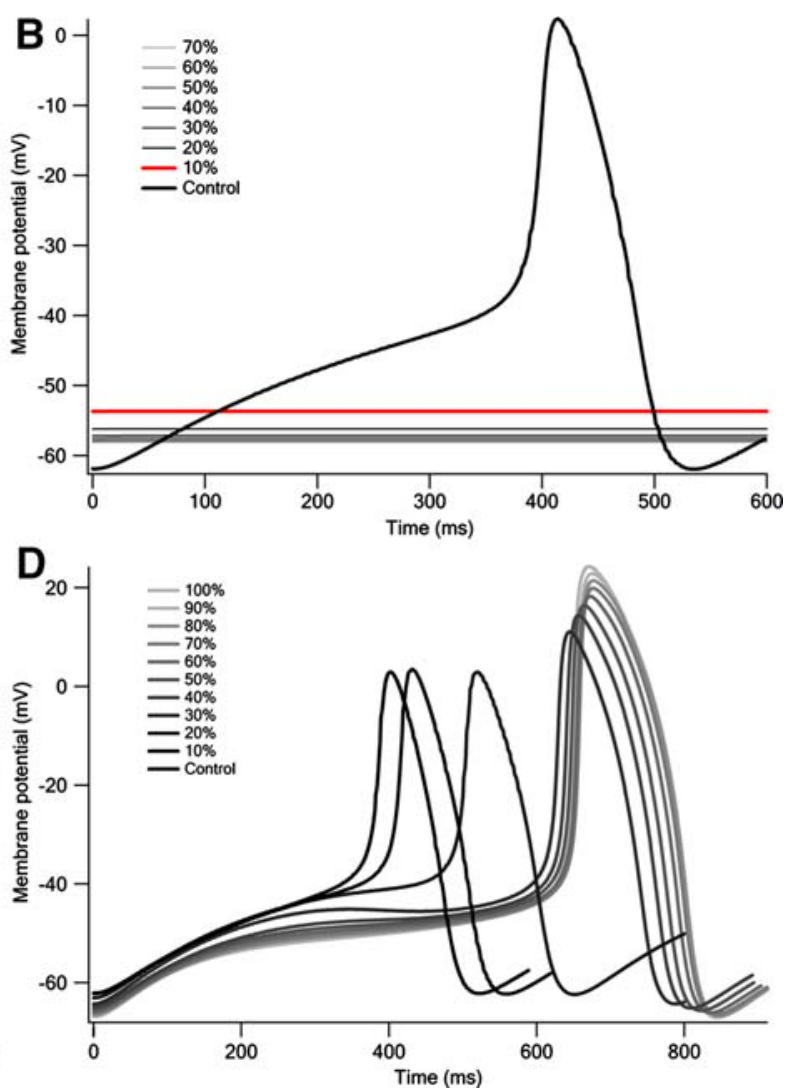

$90 \%$ and $100 \%$ toward the late embryonic stage value, owing to collapse in the balance of the ionic concentration. (C) Changes in action potential when shifting from relative activity of early embryonic $I_{\mathrm{Kr}}$ (darkest line) to that of late embryonic $I_{\mathrm{Kr}}$ (lightest line) by $10 \%$ increments. Spontaneous action potential ceased when relative activity of $I_{\mathrm{Kr}}$ was shifted by $80 \%$ (red line) or more toward late embryonic stage value. (D). Changes in action potential when relative activities of all currents except $I_{\mathrm{K} 1}$ and $I_{\mathrm{Kr}}$ were shifted from early embryonic to late embryonic values by $10 \%$ increments

model was approximately consistent with that of previous study (Yasui et al. 2001), it should be noted that the BCL of the simulated action potential might not be quantitatively accurate, because early embryonic hearts have a large range of rates in vivo.

Simulated action potential at the late embryonic stage and neonatal stage

Our models reproduced the qualitative characteristics of late embryonic and neonatal ventricular cells that have been reported (Kato et al. 1996; Kojima et al. 1990). Such characteristics include disappearance of spontaneous action potential and hyperpolarized resting membrane potential. Disappearance of the spontaneous action potential in the late embryonic stage is consistent with the results of previous studies. Spontaneous activity has not been recorded from the 
ventricular muscles of 16 -dpc or older rats (Kojima et al. 1990). The membrane potential of ventricular cells became more hyperpolarized in 18-dpc rats than in 12-dpc rats (Nagashima et al. 2001). In addition, recent studies have reported that the resting membrane potential has no statistically significant differences between late embryonic and neonatal ventricular cells (Kato et al. 1996), which is consistent with our simulated cell action potential.

Developmental changes in APD are totally different among rodents. The action potentials of the neonatal rabbit and guinea pig have a long plateau phase (Kato et al. 1996; Sanchez-Chapula et al. 1994), whereas those of the neonatal mouse and rat are immediately repolarized (Nagashima et al. 2001; Wang et al. 1996). One of the well-recognized factors that contributes to this difference is the transient outward current $\left(I_{\text {to }}\right)$, which is considered absent in the ventricular cells of the adult guinea pig under physiological conditions. A recent report classified the $I_{\text {to }}$ as either a 4-aminopyridine (AP)-sensitive $\mathrm{K}^{+}$current or a 4-APresistant $\mathrm{Ca}^{2+}$-activated current, and showed the presence of the latter current under conditions of $\mathrm{Ca}^{2+}$ overload (Nakajima et al. 2002). In the Kyoto model, $I_{\text {to }}$ was implemented as having a negligibly small amplitude, and we confirmed that decreased activity of $I_{\text {to }}$ had hardly any effect on the simulated action potential in the late embryonic, neonatal, and adult ventricular cell models. In simulation with early embryonic ventricular cells, however, we noticed that $I_{\text {to }}$ subtly affected diastolic depolarization, although the current did not block the spontaneous action potential (data not shown). Unfortunately, the presence of the $I_{\text {to }}$ in the early embryonic guinea pig has not been reported in the literature. Although we admit that the characteristics of the $I_{\text {to }}$ in embryonic mice may not be applicable to guinea pigs, we adopted the relative activity of the current in the mouse and rat for application to early embryonic, late embryonic, and neonatal ventricular cell models. The issue of $I_{\text {to }}$ therefore requires further assessment and discussion.

Despite the prominent differences in the shape of the action potential, shortening of the APD between the late embryonic stage and the neonatal stage has been observed in both guinea pigs (Nagashima et al. 2001) and rats (Kojima et al. 1990). The rapid component $\left(I_{\mathrm{Kr}}\right)$ and slow component $\left(I_{\mathrm{Ks}}\right)$ of the delayed rectifier $\mathrm{K}^{+}$current play important roles in repolarization and thus control the length of the APD; both $I_{\mathrm{Kr}}$ and $I_{\mathrm{Ks}}$ undergo very complex changes in their activities between the late embryonic and neonatal stages (Fig. 1). We estimated the relative activities of both $I_{\mathrm{Kr}}$ and $I_{\mathrm{Ks}}$ on the basis of the qualitative characteristics of these currents, including the changes in APD in response to a selective $I_{\mathrm{Kr}}$ blocker. Although qualitatively consistent, APD may not be quantitatively accurate because several relative activities were estimated on the basis of qualitative characteristics.

Roles of individual ionic currents in spontaneous action potential

Disappearance of spontaneous firing of action potential is one of the important changes in electrical activity of the ventricular cells during embryonic development. Our simulation has shown that the spontaneous action potential of early embryonic ventricular cells ceased when the relative activities of all current components were shifted by $10 \%$ or more toward the late embryonic stage value (Fig. 4A), which was roughly consistent with the previous report that spontaneous activity has not been recorded from the ventricular muscles of 16-dpc or older rats (Kojima et al. 1990). To determine the factors that contribute to the disappearance of spontaneous action potential during embryonic development, the relative activity of each current was shifted from early embryonic to late embryonic by $10 \%$ increments.

Yasui et al. (2001) implied that $I_{\mathrm{ha}}$ is important for the autonomic modulation of heart rate; the relative activity of $I_{\mathrm{ha}}$ is decreased by $82 \%$ during embryonic development and absent in adult ventricular cells. Although $I_{\text {ha }}$ is not included in the adult ventricular cell model, the Kyoto model implemented the current as part of its SA node cell model. The developmental changes in $I_{\text {ha }}$ were thus simulated by shifting the relative activity from 100 to 18 ; the decrease in $I_{\text {ha }}$ subtly affected the DSD phase and increased the BCL by $20 \mathrm{~ms}$, but did not induce disappearance of the spontaneous action potential (data not shown).

Hyperpolarization of the membrane potential via an increase in $I_{\mathrm{K} 1}$ is considered to be a major factor contributing to the disappearance of spontaneous beating (Nagashima et al. 2001). This previous finding is consistent with our result that a $10 \%$ increase in $I_{\mathrm{K} 1}$ shifted the membrane potential more negatively and stopped the spontaneity (Fig. 4B). Although hyperpolarization was not as strong when the relative activities of all current components were shifted $10 \%$ toward the late embryonic stage value (Fig. 4A), this result suggests that hyperpolarization of the membrane potential by an increase in $I_{\mathrm{K} 1}$ is the most important factor in the disappearance of the spontaneous action potential.

Application of defetilide, an $I_{\mathrm{Kr}}$ specific blocker, is reported to strongly impair the rhythm of embryonic hearts with lethal effect (Spence et al. 1994). Although 


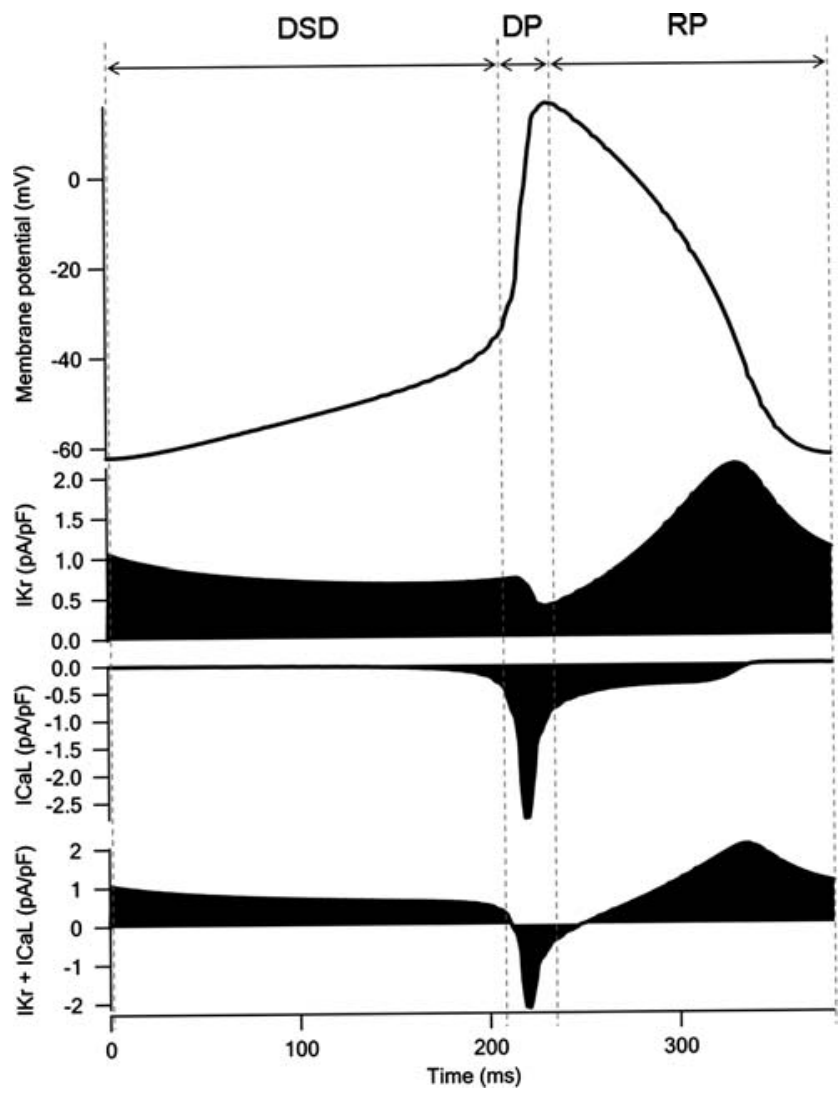

Fig. 5 Simulated action potential and ionic currents of SA node cells. Simulated action potential and changes in $I_{\mathrm{Kr}}$ current, $I_{\mathrm{CaL}}$ current, and sum of $I_{\mathrm{Kr}}$ and $I_{\mathrm{CaL}}$ accompanying the spontaneous action potential are indicated. BCL of the action potential was $382 \mathrm{~ms}$, which was shorter than that of early embryonic ventricular cells $(492 \mathrm{~ms})$. The MDP was approximately the same in the SA node cells $(-62.17 \mathrm{mV})$ and early embryonic ventricular cells $(-62.86 \mathrm{mV})$. The overshoot was $16.14 \mathrm{mV}$ in the SA node cells: this value was more positive than that in the early embryonic ventricular cells $(3.13 \mathrm{mV})$

the simulation may not be quantitatively accurate, the spontaneous action potential ceased when the relative activity of $I_{\mathrm{Kr}}$ was shifted by $80 \%$ or more toward the late embryonic stage value (Fig. 4C). Additional simulation showed that spontaneity did not disappear when shifted relative activities of all current components except $I_{\mathrm{K} 1}$ and $I_{\mathrm{Kr}}$ to the late embryonic stage value (Fig. 4D), which further indicated that developmental changes in the relative activities of $I_{\mathrm{K} 1}$ and $I_{\mathrm{Kr}}$ are the key factors in the disappearance of the spontaneous action potential.

Comparison of the spontaneous action potentials of early embryonic ventricular cells and differentiated SA node cells

The spontaneous action potential is one of the important features of electrical activity in early embryonic ventricular cells. It is well known that fully differentiated SA node cells show spontaneous action potential. Figure 5 shows the action potential of the SA node cells, as simulated by using common sets of mathematical equations; the SA node cells had a longer RP phase than early embryonic ventricular cells. The amplitude parameters of the current components in early embryonic ventricular cells were similar to those in SA node cells, but one prominent difference is that the early embryonic ventricular cells had more $I_{\mathrm{CaT}}$ and $I_{\mathrm{NaCa}}$ than did the SA node cells.

Recently, the roles of both the $I_{\mathrm{CaT}}$ and $I_{\mathrm{NaCa}}$, as well as that of $\mathrm{Ca}^{2+}$ release through the RyR channel in the SR, have been noted as important factors in diastolic depolarization of the SA node cells (Lakatta et al. 2003). In contrast, the role of these components in the early embryonic ventricular cells is a controversial issue. Most previous studies agree with the observation that the SR is scarce and poorly organized in early embryonic ventricular cells (Olivetti et al. 1980); in rats the t-tubules of the ventricular cells begin to form during postnatal development (Seki et al. 2003). A recent report showed that application of ryanodine to 9.5 -dpc mice did not affect the spontaneous $\mathrm{Ca}^{2+}$ transient (Takeshima et al. 1998), whereas another report stated that the magnitude of the $\mathrm{Ca}^{2+}$ transient was decreased after the application of ryanodine to 12 -dpc rats (Seki et al. 2003).

In addition, the role of abundant $\mathrm{Na}^{+} / \mathrm{Ca}^{2+}$ exchange in early embryonic ventricular cells remains unclarified. One previous study generated $N C X 1$-deficient mice and showed that the absence of $N C X 1$ was lethal to the embryo at approximately $9.0 \mathrm{dpc}$ as a result of abnormal cardiac development (Cho et al. 2000). Moreover, application of an inhibitor of the reverse mode of $\mathrm{Na}^{+} /$ $\mathrm{Ca}^{2+}$ exchange to 9.5-dpc mice had no substantial effect on the $\mathrm{Ca}^{2+}$ transient of the ventricular cells, indicating that $\mathrm{Ca}^{2+}$ entry by the reverse mode of $\mathrm{Na}^{+} / \mathrm{Ca}^{2+}$ exchange is not a main source of the $\mathrm{Ca}^{2+}$ transient in early embryonic ventricular cells (Liu et al. 2002). As a future prospect, by the expansion of our models it will be possible to contrive models that reflect each of these contended concepts, and we believe that comparative simulation with such models will provide novel insights into these controversial issues.

Simulation of action potential with the Kyoto and Luo-Rudy models

Spontaneous action potentials have been observed in simulations with the Kyoto and Luo-Rudy models (Fig. 3). This result strongly supports our claim that spontaneous action potential in the early embryonic 
stage can be reproduced with the same sets of mathematical equations as used in the adult model by multiplying by the corresponding relative activities. This result also supports our simulated result that lack of $I_{\text {ha }}$ and $I_{\text {to }}$ does not considerably affect spontaneous firing of the action potential, because those currents are absent in the Luo-Rudy model. Although both models have simulated spontaneous action potentials, the Kyoto model reproduced both the quantitative characteristics and qualitative behavior of previously reported experimental data (Nagashima et al. 2001) more consistently than the Luo-Rudy model.

Faster RP was observed in the Luo-Rudy model (Fig. 3B) than in the Kyoto model (Fig. 3A). Repolarization of the spontaneous action potential is mediated mostly by $I_{\mathrm{Kr}}$; therefore, fast repolarization in the Luo-Rudy model is determined by fast activation of $I_{\mathrm{Kr}}$. Whereas $I_{\mathrm{Kr}}$ in the Luo-Rudy model is described by one activation gate (Faber and Rudy 2000), $I_{\mathrm{Kr}}$ in the Kyoto model involves two activation gates and one inactivation gate (Matsuoka et al. 2003); the kinetics and parameters of $I_{\mathrm{Kr}}$ in the Kyoto model were obtained on the basis of $I_{\mathrm{Kr}}$ in SA node cells (Ono and Ito 1995).

The late half of the RP was slower in the Luo-Rudy model than in the Kyoto model; this was caused by reactivation of $I_{\mathrm{CaL}} \cdot I_{\mathrm{CaL}}$ in the Kyoto model is immediately inactivated when the membrane potential has started to repolarize from the peak of the action potential, whereas $I_{\mathrm{CaL}}$ is reactivated in the middle of the RP in the Luo-Rudy model. $I_{\mathrm{CaL}}$ in the Luo-Rudy model contains a voltage-dependent activation gate, a voltage-dependent inactivation gate, and a $\mathrm{Ca}^{2+}$ dependent gate. In contrast, the Kyoto model uses a 4state model (Shirokov et al. 1993) for both the voltagedependent gate and $\mathrm{Ca}^{2+}$-dependent gate, which can be adjusted on the basis of the kinetics of $I_{\mathrm{CaL}}$ and the action potential of rabbit SA node cells (Hagiwara et al. 1988).

The DSD phase is faster in the Luo-Rudy model than the Kyoto model. The Luo-Rudy model lacks several currents that are included in the Kyoto model; such currents include $I_{\mathrm{ha}}$ and $I_{\mathrm{bNSC}}$. The balance of $I_{\mathrm{Kr}}$ and $I_{\mathrm{bNSC}}$ determines the MDP of the spontaneous action potential in the Kyoto model (Sarai et al. 2003). Although it has been reported that $I_{\text {ha }}$ plays an important role in the spontaneous activity of early embryonic ventricular cells (Yasui et al. 2001), $I_{\text {ha }}$ plays a minor role in diastolic depolarization in the Kyoto model (Sarai et al. 2003). Hence, the difference in $I_{\mathrm{bNSC}}$ between the two models is the most important difference contributing to the increased speed of the DSD phase.
All of the our observations we have described thus far indicate that the Kyoto model reproduced the action potential in the early embryonic stage more consistently than did the Luo-Rudy model. Although the Luo-Rudy model was developed for a single cell type, the model equations in the Kyoto model were developed for two cell types: SA node cells and ventricular cells (Matsuoka et al. 2003); in this report, Matsuoka et al. intentionally used common mathematical equations, because no obvious difference has been observed in the electrophysiological properties of the currents, in terms of their kinetics. We may have taken advantage of their intention, because most currents in ventricular cells change quantitatively with similar kinetics throughout the stages of development.

\section{Limitations}

Although our primary target species for the modeling was guinea pigs and we attempted to preferentially adopt those in vitro experimental data on the guinea pigs, the model included experimental data on the rat and mouse, especially in the case of the early embryonic ventricular cell model. We intended to utilize the term "rodent" to represent all species from which we obtained experimental data, but this does not imply that the models constructed represent rodent ventricular cells in general. Hence, we admit that the results of our simulations only roughly represent developmental changes in the electrophysiological activity of rodent ventricular cells at the representative stages.

In addition, in light of our initial assumption that developmental changes in ionic currents are determined mainly by the quantitative changes in these currents, further application of the models we have constructed may need to be cautious, especially in terms of quantitative interpretation of the simulation results. Our assumption may be too abstract in regard to the ways in which several ionic channels undergo complex regulation, such as by subtype switching and alternative splicing. Despite the fact that such complex regulations affect ionic channel kinetics, the results of our simulations using models constructed only on the basis of quantitative changes were roughly consistent with action potentials previously reported in vitro (Nagashima et al. 2001; Kato et al. 1996). We thus believe that one of the important points of this study is that the developmental changes in action potential were well represented by the same sets of mathematical equations as used in the adult model, simply by multiplying by the corresponding relative activities. 


\section{Conclusions}

We assumed that developmental changes of the ion channels could be represented quantitatively as the activities of the channels in the developing rodent relative to those in the adult. Multiplication of the relative activities by the corresponding mathematical equations reproduced the developmental changes in the action potential of the rodent ventricular cell. Although both the Kyoto and Luo-Rudy models represented spontaneous action potentials, the Kyoto model reproduced action potentials in the early embryonic stage more consistently than did the Luo-Rudy model.

\section{Authors' contributions}

HI conceived the study, drafted the design, analyzed the collected data, and wrote the manuscript. YN participated both in the design of the study and implementation of the model by the E-Cell system. MT was involved in coordination and supervision of the study. Both YN and MT helped to draft the manuscript. All the authors read and approved the final manuscript.

Acknowledgements This work was supported in part by a grant-in-aid from the Ministry of Education, Culture, Sports, Science, and Technology of Japan (the Leading Project for Biosimulation and the 21st Century Center of Excellence [COE] Program: Understanding and Control of Life's Function via Systems Biology).

\section{References}

Artman M (1992) Sarcolemmal $\mathrm{Na}(+)-\mathrm{Ca} 2+$ exchange activity and exchanger immunoreactivity in developing rabbit hearts. Am J Physiol 263(5 Pt 2):H1506-H1513

Artman M, Ichikawa H, Avkiran M, Coetzee WA (1995) $\mathrm{Na}+$ / $\mathrm{Ca} 2+$ exchange current density in cardiac myocytes from rabbits and guinea pigs during postnatal development. Am J Physiol 268(4 Pt 2):H1714-H1722

Chen F, Ding S, Lee BS, Wetzel GT (2000) Sarcoplasmic reticulum $\mathrm{Ca}(2+)$ ATPase and cell contraction in developing rabbit heart. J Mol Cell Cardiol 32(5):745-755

Cho CH, Kim SS, Jeong MJ, Lee CO, Shin HS (2000) The Na+$\mathrm{Ca} 2+$ exchanger is essential for embryonic heart development in mice. Mol Cells 10(6):712-722

Chun KR, Koenen M, Katus HA, Zehelein J (2004) Expression of the IKr components KCNH2 (rERG) and KCNE2 (rMiRP1) during late rat heart development. Exp Mol Med 36(4):367-371

Couch JR, West TC, Hoff HE (1969) Development of the action potential of the prenatal rat heart. Circ Res 24(1):19-31

Davies MP, An RH, Doevendans P, Kubalak S, Chien KR, Kass RS (1996) Developmental changes in ionic channel activity in the embryonic murine heart. Circ Res 78(1):15-25
Faber GM, Rudy Y (2000) Action potential and contractility changes in $[\mathrm{Na}(+)](\mathrm{i})$ overloaded cardiac myocytes: a simulation study. Biophys J 78(5):2392-2404

Ferron L, Capuano V, Deroubaix E, Coulombe A, Renaud JF (2002) Functional and molecular characterization of a $\mathrm{T}$ type $\mathrm{Ca}(2+)$ channel during fetal and postnatal rat heart development. J Mol Cell Cardiol 34(5):533-546

Franco D, Demolombe S, Kupershmidt S, Dumaine R, Dominguez JN, Roden D, Antzelevitch C, Escande D, Moorman AF (2001) Divergent expression of delayed rectifier $\mathrm{K}(+)$ channel subunits during mouse heart development. Cardiovasc Res 52(1):65-75

Hagiwara N, Irisawa H, Kameyama M (1988) Contribution of two types of calcium currents to the pacemaker potentials of rabbit sino-atrial node cells. J Physiol 395:233-253

Huynh TV, Chen F, Wetzel GT, Friedman WF, Klitzner TS (1992) Developmental changes in membrane Ca2+ and $\mathrm{K}+$ currents in fetal, neonatal, and adult rabbit ventricular myocytes. Circ Res 70(3):508-515

Kato Y, Masumiya H, Agata N, Tanaka H, Shigenobu K (1996) Developmental changes in action potential and membrane currents in fetal, neonatal and adult guinea-pig ventricular myocytes. J Mol Cell Cardiol 28(7):1515-1522

Kilborn MJ, Fedida D (1990) A study of the developmental changes in outward currents of rat ventricular myocytes. J Physiol 430:37-60

Kiyosue T, Spindler AJ, Noble SJ, Noble D (1993) Background inward current in ventricular and atrial cells of the guineapig. Proc Biol Sci 252(1333):65-74

Klugbauer N, Welling A, Specht V, Seisenberger C, Hofmann F (2002) L-type Ca2+ channels of the embryonic mouse heart. Eur J Pharmacol 447(2-3):279-284

Kojima M, Sada H, Sperelakis N (1990) Developmental changes in beta-adrenergic and cholinergic interactions on calciumdependent slow action potentials in rat ventricular muscles. Br J Pharmacol 99(2):327-333

Lakatta EG, Maltsev VA, Bogdanov KY, Stern MD, Vinogradova TM (2003) Cyclic variation of intracellular calcium: a critical factor for cardiac pacemaker cell dominance. Circ Res 92(3):e45-e50

Linz KW, Meyer R (2000) Profile and kinetics of L-type calcium current during the cardiac ventricular action potential compared in guinea-pigs, rats and rabbits. Pflugers Arch 439(5):588-599

Liu W, Yasui K, Opthof T, Ishiki R, Lee JK, Kamiya K, Yokota M, Kodama I (2002) Developmental changes of $\mathrm{Ca}(2+)$ handling in mouse ventricular cells from early embryo to adulthood. Life Sci 71(11):1279-1292

Mahony L (1996) Regulation of intracellular calcium concentration in the developing heart. Cardiovasc Res 31 Spec No:E61-E67

Masuda H, Sperelakis N (1993) Inwardly rectifying potassium current in rat fetal and neonatal ventricular cardiomyocytes. Am J Physiol 265(4 Pt 2):H1107-H1111

Matsuoka S, Sarai N, Kuratomi S, Ono K, Noma A (2003) Role of individual ionic current systems in ventricular cells hypothesized by a model study. Jpn J Physiol 53(2):105-123

Nagashima M, Tohse N, Kimura K, Yamada Y, Fujii N, Yabu H (2001) Alternation of inwardly rectifying background $\mathrm{K}+$ channel during development of rat fetal cardiomyocytes. J Mol Cell Cardiol 33(3):533-543

Nakajima I, Watanabe H, Iino K, Saito T, Miura M (2002) Ca2+ overload evokes a transient outward current in guinea-pig ventricular myocytes. Circ J 66(1):87-92 
Niwa N, Yasui K, Opthof T, Takemura H, Shimizu A, Horiba M, Lee JK, Honjo H, Kamiya K, Kodama I (2004) Cav3.2 subunit underlies the functional T-type $\mathrm{Ca} 2+$ channel in murine hearts during the embryonic period. Am J Physiol Heart Circ Physiol 286(6):H2257-2263

Olivetti G, Anversa P, Loud AV (1980) Morphometric study of early postnatal development in the left and right ventricular myocardium of the rat. II. Tissue composition, capillary growth, and sarcoplasmic alterations. Circ Res 46(4):503-512

Ono K, Ito H (1995) Role of rapidly activating delayed rectifier $\mathrm{K}+$ current in sinoatrial node pacemaker activity. Am $\mathrm{J}$ Physiol 269(2 Pt 2):H453-H462

Puglisi JL, Wang F, Bers DM (2004) Modeling the isolated cardiac myocyte. Prog Biophys Mol Biol 85(2-3):163-178

Sanchez-Chapula J, Elizalde A, Navarro-Polanco R, Barajas H (1994) Differences in outward currents between neonatal and adult rabbit ventricular cells. Am J Physiol 266(3 Pt 2):H1184-H1194

Sarai N, Matsuoka S, Kuratomi S, Ono K, Noma A (2003) Role of individual ionic current systems in the SA node hypothesized by a model study. Jpn J Physiol 53(2):125-134

Satoh H, Delbridge LM, Blatter LA, Bers DM (1996) Surface:volume relationship in cardiac myocytes studied with confocal microscopy and membrane capacitance measurements: species-dependence and developmental effects. Biophys J 70(3):1494-1504

Seki S, Nagashima M, Yamada Y, Tsutsuura M, Kobayashi T, Namiki A, Tohse N (2003) Fetal and postnatal development of $\mathrm{Ca} 2+$ transients and $\mathrm{Ca} 2+$ sparks in rat cardiomyocytes. Cardiovasc Res 58(3):535-548

Shirokov R, Levis R, Shirokova N, Rios E (1993) Ca(2+)dependent inactivation of cardiac L-type $\mathrm{Ca} 2+$ channels does not affect their voltage sensor. J Gen Physiol 102(6):1005-1030

Spence SG, Vetter C, Hoe CM (1994) Effects of the class III antiarrhythmic, dofetilide (UK-68,798) on the heart rate of midgestation rat embryos, in vitro. Teratology 49(4):282-292

Takahashi K, Kaizu K, Hu B, Tomita M (2004) A multi-algorithm, multi-timescale method for cell simulation. Bioinformatics 20(4):538-546

Takeshima H, Komazaki S, Hirose K, Nishi M, Noda T, Iino M (1998) Embryonic lethality and abnormal cardiac myocytes in mice lacking ryanodine receptor type 2. Embo $\mathbf{J}$ 17(12):3309-3316

Wang L, Feng ZP, Kondo CS, Sheldon RS, Duff HJ (1996) Developmental changes in the delayed rectifier $\mathrm{K}+$ channels in mouse heart. Circ Res 79(1):79-85

Xie LH, Takano M, Noma A (1997) Development of inwardly rectifying $\mathrm{K}+$ channel family in rat ventricular myocytes. Am J Physiol 272(4 Pt 2):H1741-H1750

Yasui K, Liu W, Opthof T, Kada K, Lee JK, Kamiya K, Kodama I (2001) I(f) current and spontaneous activity in mouse embryonic ventricular myocytes. Circ Res 88(5):536-542

Yokoshiki H, Tohse N (2001) Developmental changes of ion channels. In: Sperelakis N, Kurachi Y, Terzic A, Cohen M (eds) Heart physiology and pathophysiology, vol 4. Academic Press, New York, pp 719-735

Zhang ZJ, Jurkiewicz NK, Folander K, Lazarides E, Salata JJ, Swanson R (1994) K+ currents expressed from the guinea pig cardiac IsK protein are enhanced by activators of protein kinase C. Proc Natl Acad Sci U S A 91(5):1766-1770 